\title{
Biosorption of hexavalent chromium from aqueous solutions by Macadamia nutshell powder
}

\author{
Vusumzi Emmanuel Pakade ${ }^{1}$ Themba Dominic Ntuli ${ }^{1}$ - Augustine Enakpodia Ofomaja ${ }^{1}$
}

Received: 20 January 2016/ Accepted: 31 March 2016/Published online: 15 April 2016

(c) The Author(s) 2016. This article is published with open access at Springerlink.com

\begin{abstract}
Macadamia nutshell biosorbents treated in three different activating agents [raw Macadamia nutshell powder (RMN), acid-treated Macadamia nutshell (ATMN) and base-treated Macadamia nutshell (BTMN)] were investigated for the adsorption of hexavalent chromium $[\mathrm{Cr}(\mathrm{VI})]$ from aqueous solutions. Fourier transform infrared spectroscopy spectra of free and $\mathrm{Cr}(\mathrm{VI})$-loaded sorbents as well as thermogravimetric analysis revealed that the acid and base treatments modified the surface properties of the sorbent. Surface characteristics were also evaluated by the scanning electron microscopy and surface area analyzer. The optimum conditions for the adsorption of $\mathrm{Cr}(\mathrm{VI})$ by sorbents were $\mathrm{pH} 2$, contact time $10 \mathrm{~h}$, adsorbent mass $0.2 \mathrm{~g}$ and concentration $100 \mathrm{mg} \mathrm{L}^{-1}$. The equilibrium data were fitted into the Langmuir, Freundlich, RedlichPeterson and Sips isotherms, and no single model could clearly explain the sorption mechanism. Maximum binding capacities of $45.23,44.83$ and $42.44 \mathrm{mg} \mathrm{g}^{-1}$ for RMN, ATMN and BTMN, respectively, were obtained. The kinetic data were analyzed using the pseudo-first, pseudosecond and Elovich kinetic models, and it was observed that the pseudo-second-order model produced the best fit for the experimental data. Macadamia nutshell sorbents showed potential as low-cost adsorbent for the removal of $\mathrm{Cr}(\mathrm{VI})$ from aqueous solution.
\end{abstract}

Keywords Macadamia $\cdot$ Chromium(VI) - Reduction · Biosorption · Treatment · Isotherms

Vusumzi Emmanuel Pakade

vusumzip@vut.ac.za

1 Department of Chemistry, Faculty of Applied and Computer Sciences, Vaal University of Technology, Private Bag x 021, Vanderbijlpark 1900, South Africa

\section{List of symbols}

$a_{\mathrm{rp}} \quad$ Redlich-Peterson equilibrium constants $\left(\mathrm{L} \mathrm{mg}^{-1}\right)^{g}$

ATMN Acid-treated Macadamia nutshell

$b \quad$ Langmuir isotherm constant $\left(\mathrm{L} \mathrm{mg}^{-1}\right)$

BET Brunauer-Emmet-Teller surface area analyzer $\left(\mathrm{m}^{2} \mathrm{~g}^{-1}\right)$

BTMN Base-treated Macadamia nutshell

$C_{e} \quad$ Concentration of $\mathrm{Cr}(\mathrm{VI})$ in solution after adsorption $\left(\mathrm{mg} \mathrm{L}^{-1}\right)$

$C_{o} \quad$ Initial concentration of $\mathrm{Cr}(\mathrm{VI})$ in $\left(\mathrm{mg} \mathrm{L}^{-1}\right)$

FTIR Fourier transform infrared spectroscopy

$g \quad$ Redlich-Peterson model exponent

$K_{\mathrm{F}} \quad$ Freundlich isotherm constant $\left(\mathrm{mg} \mathrm{g}^{-1}\right) /(\mathrm{mg}$ $\left.\mathrm{L}^{-1}\right)^{1 / n}$

$k_{\text {rp }} \quad$ Redlich-Peterson model isotherm constant $\left(\mathrm{L} \mathrm{g}^{-1}\right)$

$k_{\mathrm{s}} \quad$ Sips equilibrium constant $\left(\mathrm{L} \mathrm{mg}^{-1}\right)^{\mathrm{ms}}$

$k_{1} \quad$ Pseudo-first-order rate constant of biosorption $\left(\mathrm{L} \min ^{-1}\right.$ )

$k_{2} \quad$ Pseudo-second-order rate constant of biosorption $\left(\mathrm{g}(\mathrm{mg} \mathrm{min})^{-1}\right)$

$m \quad$ Weight of sorbent $(\mathrm{g})$

ms $\quad$ Sips model exponent

$n_{\mathrm{F}} \quad$ Freundlich exponent describing biosorption capacity and biosorption intensity

PFO Pseudo-first-order rate model

PSO Pseudo-second-order rate model

$q_{e} \quad$ Amount of $\mathrm{Cr}(\mathrm{VI})$ ions adsorbed per unit mass of adsorbent ( $\left.\mathrm{mg} \mathrm{g}^{-1}\right)$

$q_{\mathrm{m}} \quad$ Maximum metal uptake $\left(\mathrm{mg} \mathrm{g}^{-1}\right)$

$q_{\mathrm{ms}} \quad$ Sips adsorption capacity $\left(\mathrm{mg} \mathrm{g}^{-1}\right)$

$q_{t} \quad$ Metal ion uptake at time $t\left(\mathrm{mg} \mathrm{g}^{-1}\right)$

RMN Raw Macadamia nutshell powder 
TGA Thermogravimetric analysis

$V \quad$ Volume of metal solution (L)

$\alpha \quad$ Elovich initial adsorption rate constant $\left(\mathrm{mg} \mathrm{g}^{-1}\right.$ $\min ^{-1}$ )

$\beta \quad$ Elovich desorption constant $\left(\mathrm{g} \mathrm{mg}^{-1}\right)$

\section{Introduction}

The presence of toxic non-degradable heavy metals in the ecosystem, even at trace levels, presents a serious environmental health hazard (Khani et al. 2010; Gupta and Nayak 2012). Chromium may exist in several oxidation states in the environment. The hexavalent and trivalent oxidation states are the most stable in the environment. Trivalent chromium [Cr(III)] is an essential micronutrient found naturally in rocks, plants and soil, while hexavalent chromium $[\mathrm{Cr}(\mathrm{VI})]$ is rarely found in nature and is toxic (Gardea-Torresdey et al. 2000). The main sources of $\mathrm{Cr}(\mathrm{VI})$ in drinking water are of anthropogenic origin including discharges or leakages from steel and pulp mills, and from a number of industries including: paint and pigments, textile, electroplating, canning, chrome plating, leather tanning, cement dyeing and erosion of natural deposits of chromium (III) (Parvathi and Nagendran 2007).

Conventional methods including adsorption by various sorbents (Gupta et al. 2015), biosorption (Moussavi and Barikbin 2010), reduction (An et al. 2014), solvent extraction (Pagilla and Canter 1999), reverse osmosis (Lin et al. 2014) and ion exchange (Pehlivan and Cetin 2009) have been reported for chromium removal. Reduction-precipitation is the most commonly used technique for removal of $\mathrm{Cr}(\mathrm{VI})$, particularly at the industrial scale (Gupta et al. 2010). However, it is expensive as it requires large amounts of chemicals, a large piece of land and produces large quantities of chemical sludge that require skilled operators to deal with it (Gupta et al. 2010). Ion exchange is considered as an alternative; however, it too is expensive and is characterized by poor selectivity for $\mathrm{Cr}(\mathrm{VI})$ ions (Altun and Pehlivan 2012).

Biomaterials derived from agricultural waste have received much attention by researchers seeking to develop low-cost and efficient materials for adsorption of pollutants (Miretzky and Cirelli 2010; Gupta et al. 2015). Biomaterials have been used for the removal of various pollutants (Gupta et al. 2015) including dyes (Mittal et al. 2010; Dawood and Sen 2012), lead (Pholosi et al. 2013), zinc (Paduraru et al. 2015), cadmium (Gupta and Nayak 2012). Such waste materials are basically made up of lignin, cellulose and hemicellulose which usually account for exchange and complexation properties of this class of adsorbents (Ofomaja and Ho 2007). Although these adsorbents have shown promising results for the removal of pollutants from wastewater, there are still limitations encountered in their use including their low uptake capacity when used in the raw form and the release of organic components leading to a high chemical and biological oxygen demand and total organic carbon (Abdolali et al. 2014). To overcome these limitations, lignocellulosic materials are usually chemically activated to improve their properties and performance using several types of chemical reagents including basic solutions such as sodium hydroxide, calcium hydroxide and sodium carbonate and inorganic acid solutions such as hydrochloric acid, nitric acid, sulfuric acid, tartaric acid, citric acid and thioglycollic acid (Ngah and Hanafiah 2008).

Chemical treatment of biomaterials does not only aid the extraction of soluble organic compounds from lignocellulosic materials thereby enhancing chelating efficiency, but also modifies the surface chemical properties of the final product. Djilali et al. (2012) observed that $\mathrm{NaOH}$ treatment of timber sawdust not only permitted the extraction of hemicelluloses and most of the lignin but also allowed the conversion of the polyol structure into a negatively charged cellulose-based material. Dawood and Sen (2012) treated pine cone biomass with $\mathrm{HCl}$ and observed that while the surface area increased, the mean particle size decreased when compared to the untreated samples. Therefore, treatment of lignocellulosic materials with an acid or basic solution will not only modify the chemical composition of the material but also lead to the formation of new functional groups via hydrolysis or saponification of existing chemical compounds (Marshall and Johns 1996; Dhakal et al. 2005; Lu et al. 2009).

South Africa is the fourth largest producer of chromium in the world. It has a chromium reserve of over 200,000 tonnes and produced 11,000 tonnes in 2011 (Dhal et al. 2013). Chromium(VI) is known for its toxicity and carcinogenicity and has a tolerance concentration limit of below $0.1 \mathrm{mg} \mathrm{L}^{-1}$ for discharge into land surface water and $0.05 \mathrm{mg} \mathrm{L}^{-1}$ for potable water (WHO 1993). Chromium mining operations lead to the discharge of large volumes of effluent water containing chromium ions on a daily basis. Among the several methods that can be used for the removal of pollutants in effluents, adsorption methods using agricultural waste materials have gained popularity (Ofomaja and Ho 2007; Miretzky and Cirelli 2010; Gupta and Nayak 2012; Abdolali et al. 2014). However, there is a need to develop cheaper and more effective adsorbent materials for the removal of chromium from our water sources.

South Africa is the third largest producer of Macadamia in the world after Australia and Hawaii (Mogala 2014). As the growth rate of Macadamia plantations steadily increases so also is the accumulation of Macadamia shells (Moodley et al. 2007; Mogala 2014). There appears to be no real use for waste Macadamia shells except for road compaction in farms and as a source of heat. 
This paper explores the application of Macadamia shells for producing a cheaper and more effective adsorbent for removal of $\mathrm{Cr}(\mathrm{VI})$ ions from aqueous solutions. In addition, this study will also determine the effect of an acid and base treatment on the adsorption properties of Macadamia shells and how these treatments affect its ability to remove $\mathrm{Cr}(\mathrm{VI})$ from solution.

\section{Materials and methods}

\section{Chemicals and materials}

Sodium hydrogen carbonate, sodium carbonate, sodium hydroxide, hydrochloric acid, sulfuric acid, potassium nitrate and potassium dichromate were purchased from Merck Chemical Co. (Johannesburg, South Africa). All the solutions were prepared with ultrapure water from LaboStar equipment by Siemens (Warrendale, PA). All chemical reagents used were of high purity analytical grade. 1,5'-Diphenylcarbazide was purchased from SigmaAldrich (Johannesburg, South Africa). Dried $\mathrm{K}_{2} \mathrm{Cr}_{2} \mathrm{O}_{7}$ was used to prepare a $\mathrm{Cr}(\mathrm{VI})$ stock solution of $1000 \mathrm{mg} \mathrm{L}^{-1}$ in ultrapure water. Working solutions were prepared from serial dilutions of the stock solution. Macadamia nutshells were supplied by Eastern Produce Estates-SA (Pty) Ltd (Louis Trichardt, South Africa).

\section{Characterization of Macadamia nutshells}

The elemental composition of the raw and modified $M a$ cadamia nutshells was performed with a Thermo Flash 2000 series CHNS/O Organic Elemental Analyzer. The morphological evaluation of raw and modified Macadamia nutshells was done with a scanning electron microscope and energy-dispersive X-Ray spectrometer (SEM-EDS) from FEI Nova NanoLab FIB/SEM (Milpitas, CA). Thermogravimetric analysis (TGA) was performed with a PerkinElmer STA 600 Simultaneous Thermal Analyzer (Waltham, USA). The infrared absorption spectra were obtained with a PerkinElmer Spectrum 400 FT-IR/FT-NIR spectrometer (Waltham, USA). Batch adsorptions of $\mathrm{Cr}(\mathrm{VI})$ onto adsorbents were performed on a Multichannel stirrer MS-53 M model Jeio Tech (Seoul, Korea).

\section{Experimental methods}

\section{Macadamia homogenization (sample preparation)}

Macadamia nutshells were washed thoroughly with deionized water to remove the dirt and then dried in the vacuum oven at $105{ }^{\circ} \mathrm{C}$ overnight. The shells were crushed and ground to a fine powder and then sieved through a pore size of between 90 and $150 \mu \mathrm{m}$. This sample was labeled as the raw Macadamia nutshells (RMN). Part of RMN sample was divided into two parts: One part was treated with $0.1 \mathrm{M} \mathrm{HCl}$ (stirred for $3 \mathrm{~h}$ ) to remove all the nutrients from the shells and labeled acid-treated Macadamia nutshells (ATMN). The other part was treated with $0.1 \mathrm{M} \mathrm{NaOH}$ (stirred for $3 \mathrm{~h}$ ) and was labeled base-treated Macadamia nutshells (BTMN). ATMN and BTMN were washed with deionized water through a funnel until the water coming out of funnel was neutral. The samples were then dried in a vacuum oven at $105^{\circ} \mathrm{C}$ overnight.

\section{Bulk density determination and surface area measurement}

The bulk densities of the RMN, ATMN and BTMN powdered samples were determined by slowly transferring quantities of the samples into pre-weighed empty $25 \mathrm{~cm}^{3}$ density bottles. During transfer of the samples, the bottles were tapped gently to ensure that the particles settled at the bottom and that void spaces were eliminated. The surface area measurements were obtained from a Micromeritics Flow Prep 060 from Tristar instrument employing nitrogen adsorption/desorption isotherms at $-196{ }^{\circ} \mathrm{C}$.

\section{Determination of surface negative charge using Boehm method}

The total negative charge on the surface of the Macadamia powder was determined by using the modified Boehm (1994) method. Pholosi et al. (2013) stated that the 'total' negative charge could only be determined accurately on samples with a $\mathrm{pH}<3$. Subsequently, samples of RMN, ATMN and BTMN were soaked in $0.1 \mathrm{M} \mathrm{HCl}$ to bring the $\mathrm{pH}$ of the materials to below $\mathrm{pH}$ 3. The acidified samples were filtered and dried in an oven. One and half grams of Macadamia powder (RMN, ATMN or BTMN) was transferred into separate stoppered Erlenmeyer flasks, and $25 \mathrm{~mL}$ of $0.10 \mathrm{M} \mathrm{NaOH}$ was added and the contents were stirred at $300 \mathrm{rpm}$ for 16-20 h. The contents of the flasks were filtered under vacuum through a Whatman \#4 filter paper. Thereafter, $10 \mathrm{~mL}$ of the filtrate was added to $15 \mathrm{~mL}$ of $0.10 \mathrm{M} \mathrm{HCl}$ solution in the flask. The addition of excess $\mathrm{HCl}$ to the filtrate was done to prevent possible adsorption of carbon dioxide by the base and was necessary since the solutions were required to stand for extended time periods before analysis (Pholosi et al. 2013). Few drops of phenolphthalein indicator were added to each flask, and the solutions were titrated with $0.1 \mathrm{M} \mathrm{NaOH}$ until an endpoint was achieved. The results were expressed in mmoles $\mathrm{H}^{+}$ neutralized by excess $\mathrm{OH}^{-}$per gram of Macadamia powder. 


\section{Optimization of adsorption parameters}

Parameters influencing $\mathrm{Cr}(\mathrm{VI})$ adsorption onto $\mathrm{RMN}$, ATMN and BTMN were investigated. The parameters studied were the effect of initial solution $\mathrm{pH}$ (2-9), initial

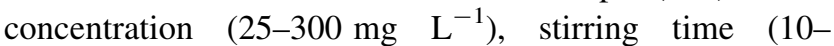
$600 \mathrm{~min})$ and sorbent dosage $(0.05-0.5 \mathrm{~g})$. All the experiments were conducted in duplicate. After adsorption, the Macadamia nutshell powder was removed from the solution by filtration through a Whatman \#4 filter paper and the un-extracted (un-adsorbed) concentration of $\mathrm{Cr}(\mathrm{VI})$ was measured at a wavelength of $540 \mathrm{~nm}$ with a UV-visible spectrometer ( $180^{+}$, PG Instruments) with 1,5'-diphenylcarbazide as a complexing agent in acidic medium (Greenberg et al. 1992). In an acidic medium, diphenylcarbazide reacts with $\mathrm{Cr}(\mathrm{VI})$ to produce a $\mathrm{Cr}(\mathrm{III})-$ diphenylcarbazone complex as indicated by the expression below (Pehlivan and Cetin 2009). Total chromium was measured using an atomic absorption spectrophotometer AA-7000 from Shimadzu (Kyoto, Japan).

$$
\begin{aligned}
2 \mathrm{Cr}_{2} \mathrm{O}_{4}^{2-}+3 \mathrm{H}_{4} \mathrm{~L}+8 \mathrm{H}^{+} \rightarrow & \mathrm{Cr}(\mathrm{HL})_{2}^{+}+3 \mathrm{Cr}^{3+}+\mathrm{H}_{2} \mathrm{~L} \\
& +8 \mathrm{H}_{2}
\end{aligned}
$$

where $\mathrm{H}_{4} \mathrm{~L}$ is 1,5-diphenylcarbazide and $\mathrm{H}_{2} \mathrm{~L}$ is diphenylcarbazone.

The removal efficiency of $\mathrm{Cr}(\mathrm{VI})$ (\% removal) and the maximum binding capacity $\left(q_{e}, \mathrm{mg} \mathrm{g}^{-1}\right)$ of the sorbents were calculated using Eqs. 1 and 2, respectively.

$R(\%)=\frac{\left(C_{o}-C_{e}\right)}{C_{o}} \times 100$

$q_{e}=\frac{V\left(C_{o}-C_{e}\right)}{m}$

where $C_{o}$ is the initial concentration of $\mathrm{Cr}(\mathrm{VI})$ in $\left(\mathrm{mg} \mathrm{L}^{-1}\right)$ and $C_{e}$ is the concentration of $\mathrm{Cr}(\mathrm{VI})$ in solution after adsorption $\left(\mathrm{mg} \mathrm{L}^{-1}\right), q_{e}$ is the adsorbed $\mathrm{Cr}(\mathrm{VI})\left(\mathrm{mg} \mathrm{g}^{-1}\right.$ adsorbent) on the sorbent, $m$ is the weight of sorbent $(\mathrm{g})$ and $V$ is the volume of metal solution $(L)$.

\section{Adsorption isotherms and kinetic modeling}

In order to relate the concentration of the adsorbate in the liquid and the amount adsorbed on the sorbent surface, several models are used to describe the phenomena (Langmuir 1918; Freundlich and Helle 1939; Redlich and Peterson 1959). In this study, four models Langmuir, Freundlich, Redlich-Peterson and Sips were used in their nonlinear forms. The Langmuir model assumes a monolayer coverage of a homogenous adsorbent surface by the adsorbate (Langmuir 1918), and Langmuir isotherm equation is given below. $q_{e}=\frac{q_{\mathrm{m}} b C_{e}}{\left(1+b C_{e}\right)}$

where $b$ the Langmuir isotherm constant $\left(\mathrm{L} \mathrm{mg}^{-1}\right), q_{\mathrm{m}}$ is the maximum metal uptake $\left(\mathrm{mg} \mathrm{g}^{-1}\right), q_{e}$ and $C_{e}$ as previously described. The dimensionless parameter, $R_{L}$, also known as the equilibrium parameter or separation factor given by Eq. 4 (Webber and Chakkravorti 1974) was calculated and used to interpret adsorption conditions from the Langmuir isotherm.

$R_{L}=\frac{1}{\left(1+b C_{o}\right)}$

The $R_{L}$ parameter gives information on the nature of adsorption, where $0<R_{L}<1$ is regarded as favorable adsorption, $R_{L}>1$ is unfavorable, $R_{L}=0$ is irreversible and $R_{L}=1$ implies linear adsorption (Webber and Chakkravorti 1974). The Freundlich model relates the sorption of an adsorbate to heterogeneous surfaces, and it assumes a multilayer adsorption (Freundlich and Helle 1939). The equation is given below.

$Q_{e}=K_{\mathrm{F}} C_{e}^{1 / n}$

where $K_{\mathrm{F}}$ is the Freundlich constant $\left[\left(\mathrm{mg} \mathrm{g}^{-1}\right) /\left(\mathrm{mg} \mathrm{L}^{-1}\right)^{1 / \mathrm{n}}\right]$ and $n_{\mathrm{F}}$ the Freundlich exponent describing biosorption capacity and biosorption intensity, respectively.

The Redlich-Peterson model is a three-parameter Langmuir-Freundlich hybrid isotherm with linear dependence on the concentration in the numerator and exponential function in the denominator ( $\mathrm{Ng}$ et al. 2002). The nonlinear form equation is supplied below (Redlich and Peterson 1959).

$q_{e}=\frac{K_{\mathrm{rp}} C_{e}}{\left(1+a_{\mathrm{rp}} C_{e}^{g}\right)}$

where $k_{\mathrm{rp}}\left(\mathrm{L} \mathrm{g}^{-1}\right)$ and $a_{\mathrm{rp}}\left(\mathrm{L} \mathrm{mg}^{-1}\right)^{g}$ are equilibrium constants and $g$ is the Redlich-Peterson model exponent. As $g$ tends to zero, the model describes Freundlich, and as $g$ gets closer to 1 , the model describes Langmuir isotherm.

Sips is a combined form of Freundlich and Langmuir isotherm equations and can be expressed as in Eq. 7

$q_{e}=\frac{q_{\mathrm{ms}} \cdot K_{\mathrm{s}} \cdot C_{e}^{\mathrm{ms}}}{\left(1+K_{\mathrm{s}} \cdot C_{e}^{\mathrm{ms}}\right)}$

where $q_{\mathrm{ms}}\left(\mathrm{mg} \mathrm{g}^{-1}\right)$ and $k_{\mathrm{s}}\left(\mathrm{L} \mathrm{mg}^{-1}\right)^{\mathrm{ms}}$ are Sips adsorption capacity and equilibrium constant, respectively. The Sips model translates to Langmuir when $\mathrm{ms}=1$ and to Freundlich when ms approaches zero.

Several kinetic models are used to investigate the processes controlling biosorption of adsorbate as well as the rate of mass transfer. Pseudo-first order (PFO), pseudosecond order (PSO) and Elovich models were employed to 
fit the experimental data. The equations for the models in their nonlinearized form are supplied below.

The PFO rate equation (also, known as Lagergren equation) and the PSO kinetic model (Ho and McKay 1999) are represented in Eqs. 8 and 9.

$q_{t}=q_{e}\left(1-\exp _{1}^{-k t}\right)$

$q_{t}=\frac{t k_{2} \cdot q_{e}^{2}}{\left(1+k_{2} t q_{e}\right)}$

where $q_{t}\left(\mathrm{mg} \mathrm{g}^{-1}\right)$ is the metal ion uptake at time $t, k_{1}$ $\left(\min ^{-1}\right)$ is the PFO rate constant of biosorption and $k_{2}$ $\left[g(\mathrm{mg} \mathrm{min})^{-1}\right]$ is the PSO rate constant of biosorption.

The Elovich kinetic model represented by Eq. 10 describes the chemisorption of adsorbates on solid surface without desorption of products.

$q_{t}=\frac{1}{\beta}(\operatorname{Ln}(\alpha \beta)+\operatorname{Ln} t)$

where $\alpha\left(\mathrm{mg} \mathrm{g}^{-1} \mathrm{~min}^{-1}\right)$ and $\beta\left(\mathrm{g} \mathrm{mg}^{-1}\right)$ are the initial adsorption rate and the desorption constant, respectively.

\section{Results and discussion}

\section{Material characterization}

Plant materials contain, among other components, pigments, resin acids, lignin, sugars, alkaloids and water soluble tannins (Wartelle and Marshall 2000). During treatment of plant materials with aqueous basic or acidic solutions, parts of the components are extracted from the plant material leaving behind void spaces (Ofomaja et al. 2010). In addition, hydrolysis of condensed functionalities may occur, particularly in the case of a base extraction, and this process may result in the formation of a more negatively charged surface (Lu et al. 2009; Dawood and Sen 2012). The void spaces act as channels for metal uptake. Therefore, as more components are extracted, the larger the void spaces and the lower is the bulk density. However, this process also decreases the number of available adsorption sites on the material and therefore the reactions must be controlled. Treatment of Macadamia nutshell sorbents with $\mathrm{HCl}$ and $\mathrm{NaOH}$ produced different results on the amount of cellulose and hemicellulose extracted. $\mathrm{NaOH}$ led to the extraction of most hemicellulose components (Table 1).

The bulk densities for RMN, ATMN and BTMN obtained were $0.612,0.584$ and $0.574 \mathrm{~g} \mathrm{~cm}^{-3}$, respectively (Table 1). RMN had a higher bulk density than ATMN and BTMN. The percentage decrease in bulk density after treatment with $0.1 \mathrm{M} \mathrm{NaOH}$ and $0.1 \mathrm{M} \mathrm{HCl}$ was 6.2 and $4.6 \%$, respectively. More extractives were removed by treatment with $\mathrm{NaOH}$, implying that Macadamia contains more base-soluble extractives (hemicellulose fraction) than those that are acid soluble. A much higher percentage decrease of 31.0, 36.4 and $60.1 \%$ in bulk density has been reported when corn cob, soybean hull and almond hull were treated, respectively, with $0.1 \mathrm{M} \mathrm{NaOH}$ for $1 \mathrm{~h}$ (Wartelle and Marshall 2000). The lower values obtained with Macadamia could be due to inefficient extraction process or that Macadamia does not contain a high percentage of extractives that could be removed by either acid or basic treatment. The surface area of RMN, ATMN and BTMN was $0.018,0.065$ and $0.546 \mathrm{~m}^{2} \mathrm{~g}^{-1}$, respectively. These values were comparable to other waste materials as reported in the literature (Basal et al. 2009).

Determination of the surface negative charge (e.g., carboxylic groups) is important to ascertain the potential suitability of natural materials for adsorption of metal ions. The surface negative charge values for RMN, ATMN and BTMN were 2.39, 2.35 and $6.67 \mathrm{mmol} \mathrm{g}^{-1}$, respectively. These results suggest that Macadamia has a low carboxylic content. No major difference between the RMN and ATMN surface negative charge values was observed. BTMN exhibited the highest surface negative charge of $6.67 \mathrm{mmol} \mathrm{g}^{-1}$ which can be attributed to the formation of ionic groups during hydrolysis (Lu et al. 2009; Dawood and Sen 2012) and the higher percent of hemicellulose extracted leading to the formation of negatively charged cellulose-based materials (Table 1).

\section{Elemental analysis of RMN, ATMN and BTMN}

Table 1 also shows the percent of $\mathrm{C}, \mathrm{H}, \mathrm{N}, \mathrm{O}$ and ratio of $\mathrm{O} / \mathrm{C}$ (atomic) for RMN, ATMN and BTMN. The percentage of oxygen was obtained by difference. The results of the elemental analysis showed that RMN, ATMN and BTMN were mainly composed of carbon, hydrogen and oxygen. A similar composition was reported for other lignocellulosic compounds such as walnut shells (Altun and Pehlivan 2012). The O/C ratio was lowest for ATMN and could imply that acid treatment had a high affinity for oxygen-containing groups.

\section{Fourier transform infrared (FTIR) spectra and thermogravimetric analysis (TGA)}

Figure 1a-c displays the FTIR spectra of RMN, ATMN and BTMN before and after adsorption of $\mathrm{Cr}(\mathrm{VI})$. The RMN, ATMN and BTMN spectra before adsorption showed similar characteristics except for differences caused by the treatments. The notable differences (deformations, intensities and shifts) in RMN, ATMN and BTMN before adsorption were observed at the following 
Table 1 Characteristics of adsorbents used in this study

\begin{tabular}{|c|c|c|c|}
\hline & \multicolumn{3}{|c|}{ Adsorbents } \\
\hline & RMN & ATMN & BTMN \\
\hline Bulk density $\left(\mathrm{g} \mathrm{mL}^{-1}\right)$ & 0.612 & 0.584 & 0.574 \\
\hline Surface negative charge $\left(\mathrm{mmol} \mathrm{g}^{-1}\right)$ & 2.39 & 2.35 & 6.67 \\
\hline Point zero charge & 6.25 & 6.42 & 6.70 \\
\hline BET surface area $\left(\mathrm{m}^{2} \mathrm{~g}^{-1}\right)$ & 0.018 & 0.065 & 0.546 \\
\hline Cellulose $(\%)$ & 34.48 & 29.54 & 40.64 \\
\hline Hemicellulose $(\%)$ & 21.48 & 24.31 & 17.47 \\
\hline Lignin $(\%)$ & 11.91 & 31.90 & 31.68 \\
\hline \multicolumn{4}{|l|}{ Ultimate analysis } \\
\hline$\% \mathrm{C}$ & 47.35 & 50.99 & 47.49 \\
\hline$\% \mathrm{H}$ & 5.52 & 5.76 & 5.66 \\
\hline$\% \mathrm{~N}$ & 0.22 & 0.90 & 0.25 \\
\hline$\% \mathrm{O}^{\mathrm{a}}$ & 46.91 & 42.35 & 46.60 \\
\hline $\mathrm{O} / \mathrm{C}$ & 0.991 & 0.831 & 0.981 \\
\hline
\end{tabular}

${ }^{\mathrm{a}}$ Calculated by difference

wavenumbers, 3339, 2925, 1740, 1452, 1241 and $1026 \mathrm{~cm}^{-1}$. These could be attributed to the presence of hydrogen-bonded hydroxyl $(\mathrm{OH})$ groups due to the cellulose structure (Zhao et al. 2013), aliphatic (C-H), carboxyl group $(\mathrm{C}=\mathrm{O})$, methoxyl $\left(\mathrm{C}-\mathrm{O}-\mathrm{CH}_{3}\right)$, hydroxyl $(\mathrm{C}-\mathrm{OH})$ bending of phenolic structure in lignin (Yang et al. 2007) and $-\mathrm{C}-\mathrm{O}$ functional groups, respectively. The band intensity at $2925 \mathrm{~cm}^{-1}$ decreased in the order $\mathrm{RMN}>\mathrm{ATMN}>\mathrm{BTMN}$ suggesting that the base extraction removed more aliphatic compounds from the lignin structure. Lu et al. (2009) also observed that alkaline pretreatment of orange peel caused a degradation of cellular compounds. The spectra of RMN, ATMN and BTMN before adsorption were further characterized by an asymmetric broad band at $1637 \mathrm{~cm}^{-1}$ ascribed to the presence of carboxylate groups (Yang and Chen 2008; Bermudez et al. 2012). The broad band at $1637 \mathrm{~cm}^{-1}$ decreased in intensity and split into two bands after $\mathrm{Cr}(\mathrm{VI})$ loading signifying its involvement in $\mathrm{Cr}(\mathrm{VI})$ removal in all three sorbents. The shape of the splits in RMN and ATMN were similar but different to that of BTMN, an indication that the latter has slightly different surface characteristics. In addition, the decrease in intensities and shapes of the band at $1455 \mathrm{~cm}^{-1}$ in all three materials implied that the methoxyl group was also involved in $\mathrm{Cr}(\mathrm{VI})$ removal. Similar observations were reported in the literature where the changes in intensities and shifts of absorption bands at 1637, 1454 and $1244 \mathrm{~cm}^{-1}$ were attributed to oxidation of lignin when contacted by $\mathrm{Cr}$ (VI) ions (Yang et al. 2007; Albadarin et al. 2011), resulting in reduction of $\mathrm{Cr}(\mathrm{VI})$ to $\mathrm{Cr}$ (III). The differences observed in FTIR spectra of RMN, ATMN and BTMN before and after adsorption of $\mathrm{Cr}(\mathrm{VI})$ confirm participation of functional groups in the removal of $\mathrm{Cr}(\mathrm{VI})$ by the materials.

Thermogravimetric analysis (TGA) of RMN, ATMN and BTMN was conducted to evaluate the change in percentage weight as a function of temperature (Fig. 2). Thermal degradation of plant biomass can be categorized into four successive individual stages, namely moisture evolution, and the decomposition of hemicelluloses, cellulose and lignin (Paduraru et al. 2015). The first stage of percentage weight loss occurred at about $120{ }^{\circ} \mathrm{C}$ estimated at 12,2 and $3 \%$ for RMN, ATMN and BTMN, respectively, was ascribed to evaporation of absorbed water. The higher \%weight loss for RMN can be attributed to the hemicellulose content of the material. The amount of adsorbed water in plant material is a measure of the hydrophilic components in its structure. The hydroxyl groups of the hemicellulose can associate with water molecules via hydrogen bonding, thereby leading to higher water content (Azwa and Yousif 2013). On treatment of the RMN with acid and base solutions, leaching out of plant components occurred, releasing part of the hemicellulose components into the extracting solvents, thereby reducing the ability of the materials to associate with water molecules. This will account for the lower moisture loss of the treated samples over the RMN sample. The second stage which took place at about $120-310{ }^{\circ} \mathrm{C}$ quantified at $16 \%$ (RMN) and $13 \%$ (ATMN) and $24 \%$ (BTMN) was due to loss of volatile compounds (such as $\mathrm{CH}_{4}, \mathrm{CO}_{2}, \mathrm{CO}, \mathrm{H}_{2}$ ) and hemicellulose degradation (Rangabhashiyam and Selvaraju 2015a). The third stage due to cellulose degradation was observed at about $310-380{ }^{\circ} \mathrm{C}$ for RMN (29\%) and ATMN (35\%), but come earlier for BTMN (22\%) at 
Fig. 1 FTIR spectra of RMN (a), ATMN (b) and BTMN (c) before and after $\mathrm{Cr}(\mathrm{VI})$ biosorption
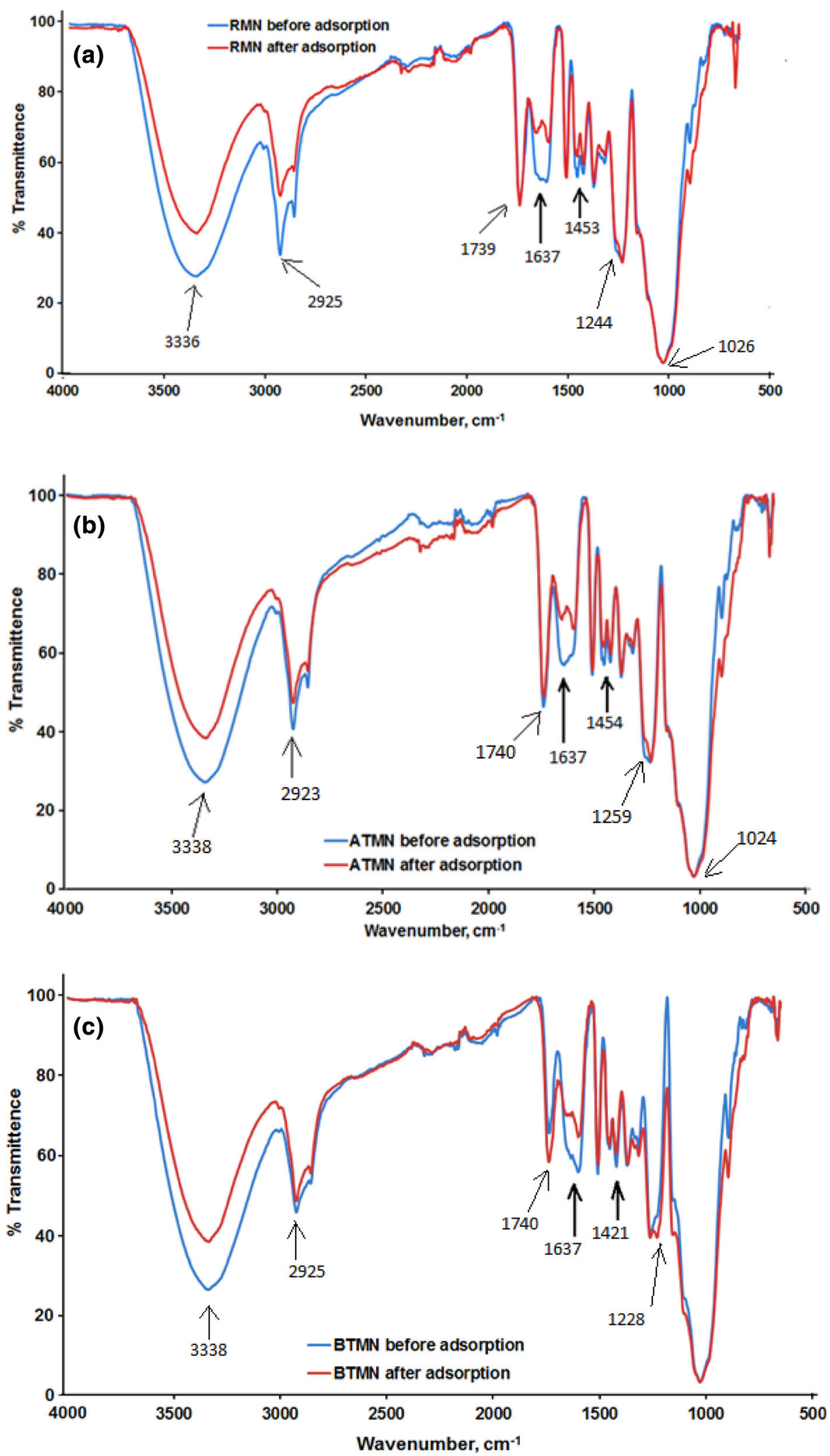

310-365 ${ }^{\circ} \mathrm{C}$. The derivative spectra for RMN, ATMN and BTMN are shown in Fig. 2b. ATMN and BTMN showed two distinct decomposition peaks, while RMN had two decomposition peaks $\left(370{ }^{\circ} \mathrm{C}\right)$ and a shoulder. The difference in decomposition peak shapes and decomposition temperatures further emphasized that chemical 
Fig. 2 Thermogravimetric analysis (a) and derivative weight percent (b), for RMN, ATMN and BTMN
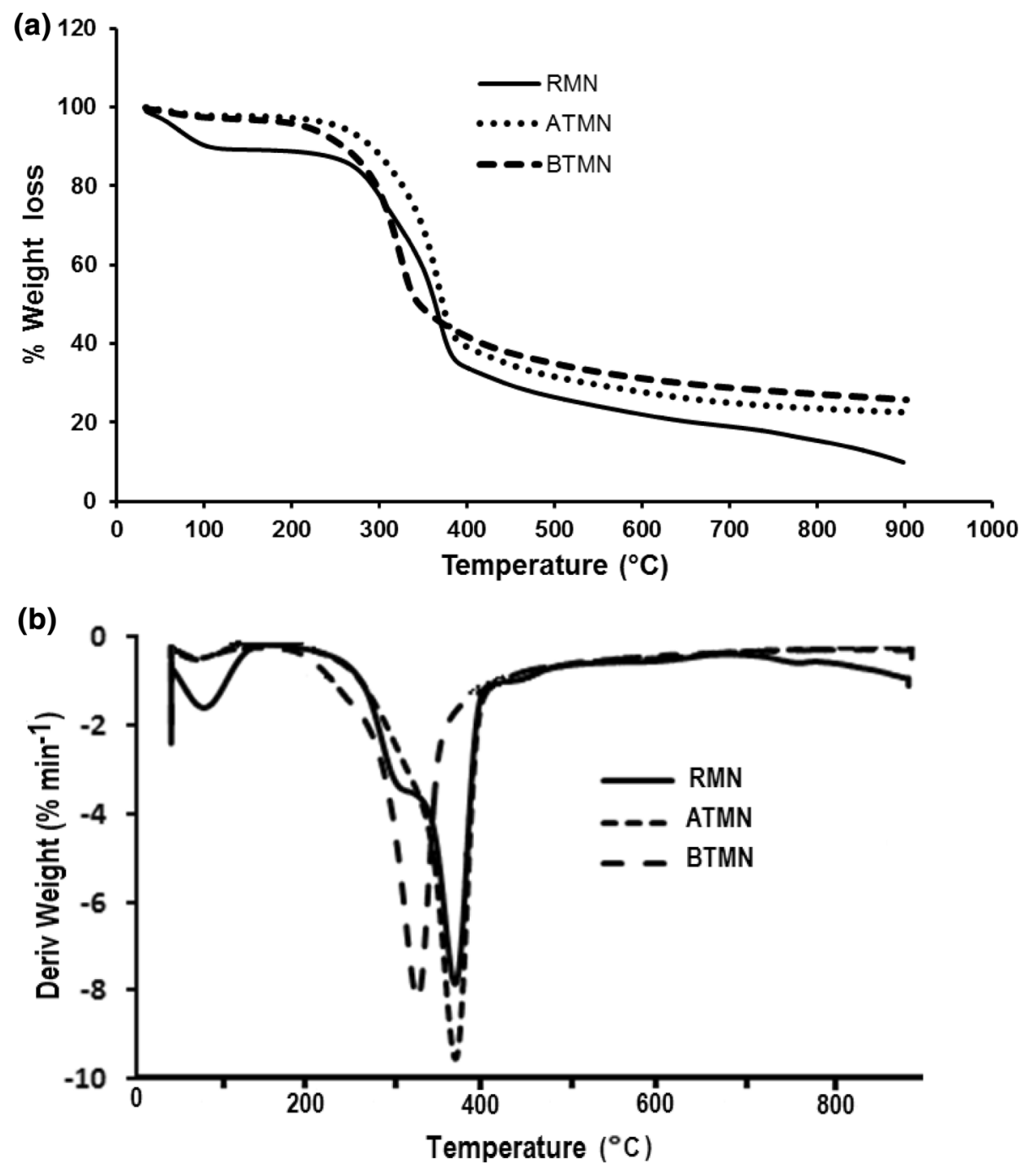

modification affected the chemical makeup of sorbents (Dhakal et al. 2005). It can then be concluded that chemical extraction produced major changes in the chemical composition of RMN.

The morphology and structure of RMN, ATMN and BTMN were characterized with scanning electron microscope (SEM). The SEM images revealed that the materials consisted of flaky long fold-like structures (Fig. 3a-c), which are typical of plant materials (Zhao et al. 2013). The structural backbone of the materials was not greatly altered since they all retained their flakiness, suggesting that the treatment methods were not excessively harsh to completely destroy the materials. SEM-EDS images confirm that the Macadamia shells consist of $\mathrm{C}$ and $\mathrm{O}$ as the main elements with no traces of heavy metals except for Au and $\mathrm{Pd}$ that originated from the coating used for SEM sample preparation.

\section{Adsorption results}

\section{Effect of $p H$}

The uptake of $\mathrm{Cr}(\mathrm{VI})$ ion by the RMN, ATMN and BTMN was evaluated at different $\mathrm{pH}$ values ranging from 2 to 9 , while keeping other parameters constant. The sorption of Cr(VI) by RMN, ATMN and BTMN was favored at acidic conditions and showed a strong dependence on $\mathrm{pH}$ as it decreased with increase in $\mathrm{pH}$ from 2 to 9 (Fig. 4a). Similar observations have been made in the literature (Deng and Ting 2005; Yang and Chen 2008; Liu and Huang 2011; Ramrakhiani et al. 2011). The percent removal of total chromium at pH 2 was 65, 62 and $50 \%$ for ATMN, RMN and BTMN, respectively. Figure $4 \mathrm{~b}-\mathrm{d}$ shows that at $\mathrm{pH} 2$ some of the $\mathrm{Cr}(\mathrm{VI})$ was not adsorbed by the sorbents, but converted to $\mathrm{Cr}$ (III). As the $\mathrm{pH}$ was raised from 3 to 9 , the 
Fig. 3 Scanning electron microscope and EDS images of $\operatorname{RMN}(\mathbf{a})$, ATMN (b) and BTMN (c)
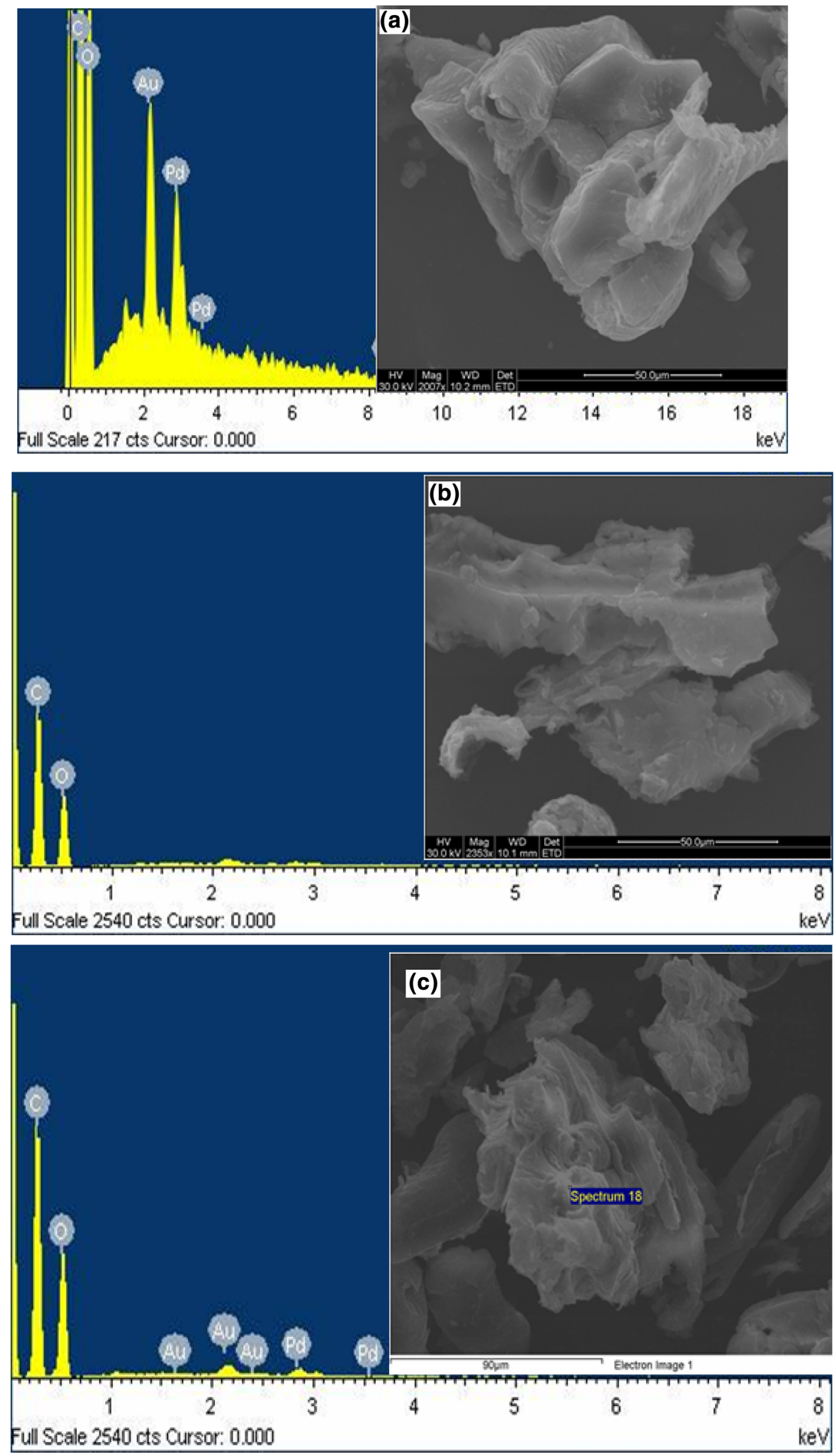

Full Scale 2540 cts Cursor: 0.000 
amount of $\mathrm{Cr}$ (III) present in solution decreased, implying that there was less reduction at these pHs. The percent $\mathrm{Cr}$ (VI) removal at $\mathrm{pH}$ 3-9 also decreased due to electrostatic repulsion by negatively charged hydroxyl ions. Yang and Chen (2008) stated that at strongly acidic conditions and in the presence of materials with electron-donating groups, $\mathrm{Cr}(\mathrm{VI})$ can be reduced to $\mathrm{Cr}$ (III). Therefore, it can be concluded that Macadamia adsorbents used in this study contained electron-donating groups which were capable of reducing $\mathrm{Cr}(\mathrm{VI})$ to $\mathrm{Cr}(\mathrm{III})$ in acidic conditions. $\mathrm{Cr}(\mathrm{VI})$ is an anionic species which may exist as $\mathrm{HCrO}_{4}{ }^{-}, \mathrm{Cr}_{2} \mathrm{O}_{7}{ }^{2-}$, $\mathrm{Cr}_{3} \mathrm{O}_{10}{ }^{2-}, \mathrm{Cr}_{4} \mathrm{O}_{13}{ }^{2-}$ or $\mathrm{CrO}_{4}{ }^{-}$at different $\mathrm{pHs}$ and concentrations (Garg et al. 2007). $\mathrm{HCrO}_{4}{ }^{-}$is the dominant species in acidic conditions due to the hydrolysis reaction of the dichromate ion $\left(\mathrm{Cr}_{2} \mathrm{O}_{7}{ }^{2-}\right)$ (Basal et al. 2009) and as the $\mathrm{pH}$ increases $\mathrm{HCrO}_{4}{ }^{-}$shifts to $\mathrm{Cr}_{2} \mathrm{O}_{7}{ }^{2-}$ and $\mathrm{CrO}_{4}{ }^{2-}$ species (Basal et al. 2009). $\mathrm{HCrO}_{4}{ }^{-}$was the dominant species at $\mathrm{pH} 2$, and $\mathrm{pH} 2$ was used in subsequent experiments.

According to Saha and Orvig (2010), there are four mechanisms with which biomaterials may sequestrate Cr(VI) from aqueous solutions, viz., (1) adsorption resulting from electrostatic attraction of anionic $\mathrm{Cr}(\mathrm{VI})$ by the biomaterial; (2) adsorption of $\mathrm{Cr}(\mathrm{VI})$ followed by complete reduction of $\mathrm{Cr}(\mathrm{VI})$ on the surface to $\mathrm{Cr}(\mathrm{III})$; (3) anionic
$\mathrm{Cr}(\mathrm{VI})$ is adsorbed, and other fraction of $\mathrm{Cr}(\mathrm{VI})$ is reduced to $\mathrm{Cr}$ (III) and subsequently adsorbed on the surface of the biomaterial; (4) part of $\mathrm{Cr}(\mathrm{VI})$ is adsorbed, and the other fraction is reduced and released back into solution. Therefore, the mode of removal of $\mathrm{Cr}(\mathrm{VI})$ by $\mathrm{RMN}$, ATMN and BTMN can be classified under category 4 (reduction-biosorption process). The amount of $\mathrm{Cr}$ (III) released back into solution at $\mathrm{pH} 2$ decreased in the order BTMN $>$ RMN $>$ ATMN. The final $\mathrm{pH}$ after adsorption of Cr(VI) by RMN, ATMN, and BTMN was also recorded. The change in $\mathrm{pH}\left(\mathrm{pH}_{\mathrm{f}}-\mathrm{pH}_{\mathrm{i}}\right)$ was plotted versus initial $\mathrm{pH}_{\mathrm{i}}$ and the point where the graph intersect the $X$-axis was reported as the $\mathrm{pH}_{\mathrm{pzc}}$. The $\mathrm{pH}_{\mathrm{pzc}}$ values obtained for $\mathrm{RMN}$, ATMN and BTMN were 6.25, 6.42 and 6.70, respectively. For all three materials, the final $\mathrm{pH}$ was higher than the initial $\mathrm{pH}$ when the initial concentration was lower than 6.25, 6.42 and 6.70 for RMN, ATMN and BTMN, respectively, and this was attributed to exhaustion of $\mathrm{H}^{+}$ during oxidation process (Sun et al. 2013). Adsorbents that can effectively reduce $\mathrm{Cr}(\mathrm{VI})$ to $\mathrm{Cr}(\mathrm{III})$ followed by immobilization of $\mathrm{Cr}$ (III) onto the sorbents are sought after and development of such adsorbents could be a breakthrough in dealing with $\mathrm{Cr}(\mathrm{VI})$ contamination (Deng and Ting 2005). However, the intrinsic complexity of biomaterials still makes it difficult to fully understand the
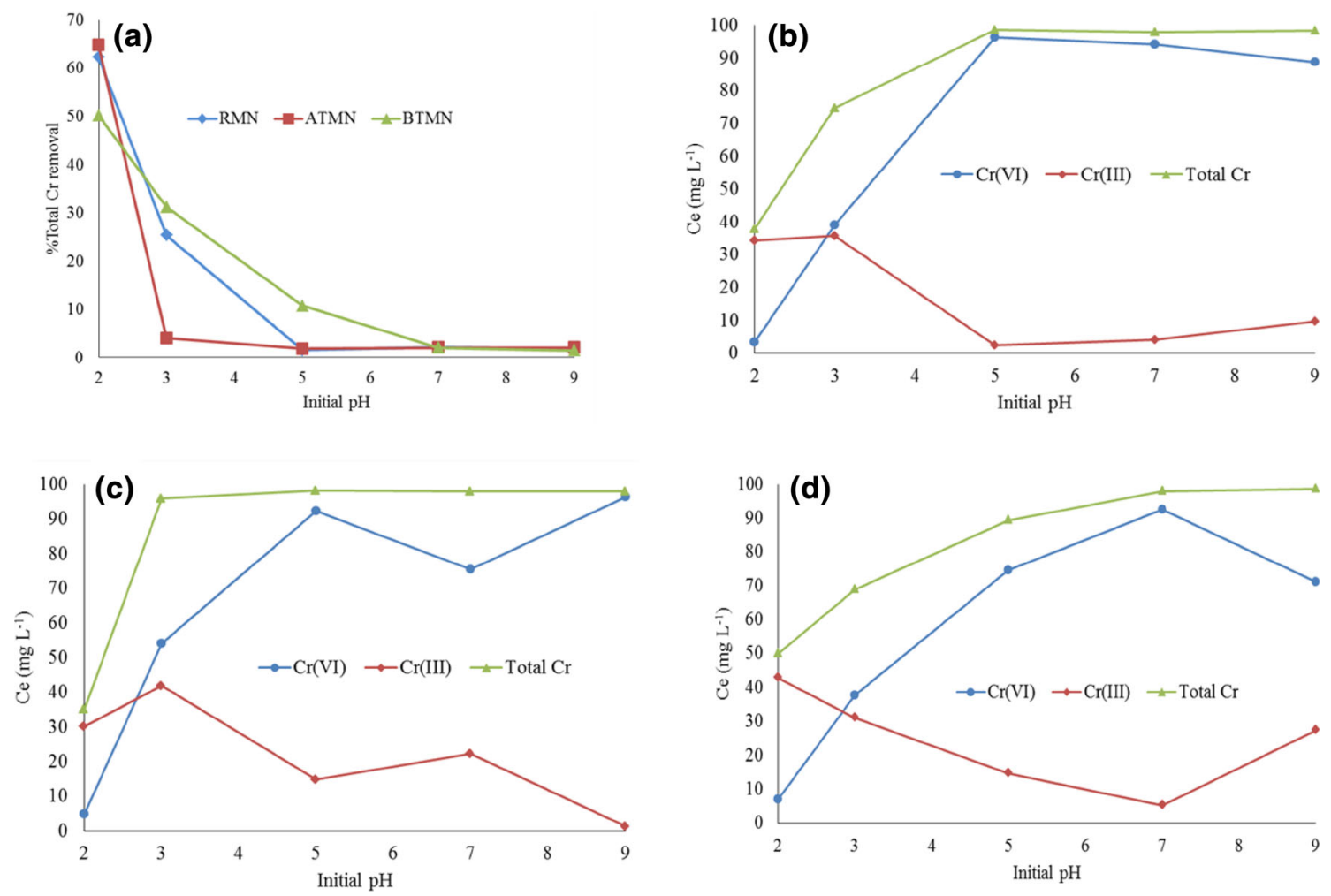

Fig. 4 Effect of pH on chromium removal by RMN, ATMN and BTMN (a), RMN (b), ATMN (c), and BTMN (d) (conditions: amount of adsorbent $0.2 \mathrm{~g}$; solution volume $25 \mathrm{~mL}$; contact time $2 \mathrm{~h}$; concentration of solution $100 \mathrm{mg} \mathrm{L}^{-1}$ ) 
reaction parameters affecting the reduction-sorption process (Deng and Ting 2005) even though some complexing groups (for $\mathrm{Cr}(\mathrm{III})$ ) and redox active centers for $\mathrm{Cr}(\mathrm{VI})$ reduction could be deduced (Liu and Huang 2011).

\section{Effect of concentration}

Figure 5 shows the effect of concentration on the adsorption of $\mathrm{Cr}(\mathrm{VI})$ by Macadamia nutshell powder. The calculations revealed that almost $100 \%$ of $\mathrm{Cr}(\mathrm{VI})$ removal was achieved at low concentrations $\left(25-100 \mathrm{mg} \mathrm{L}^{-1}\right)$ for all three sorbents (data not shown). When the concentration was increased from 100 to $300 \mathrm{mg} \mathrm{L}^{-1}$, the percent removal of $\mathrm{Cr}(\mathrm{VI})$ decreased to about $40 \%$ for all materials, while adsorption capacities increased with increase in concentration. The decrease in sorption of $\mathrm{Cr}(\mathrm{VI})$ at high concentration was due to the saturation of active binding sites (Basal et al. 2009; Gupta and Rastogi 2009). The results of adsorption capacity $\left(\mathrm{mg} \mathrm{g}^{-1}\right)$ versus initial concentration are plotted in Fig. 5. The maximum calculated binding capacities $\left(q_{e}\right)$ obtained at $200 \mathrm{mg} \mathrm{L}^{-1}$ for RMN, ATMN and BTMN were 42.53, 40.60 and $37.49 \mathrm{mg} \mathrm{g}^{-1}$, respectively. Equilibrium concentration and adsorption capacity results were fitted in different sorption isotherms.

\section{Biosorption equilibrium studies}

Table 2 shows Langmuir, Freundlich, Sips and RedlichPeterson isotherm constants obtained after fitting equilibrium concentration and adsorption capacity values into the models. Nonlinear forms of the models equations were used to plot the data using KyPlot 2.0 software (quasiNewton algorithm). The Langmuir model biosorption capacities $\left(q_{m}\right)$ were $45.23,44.83$ and $42.44 \mathrm{mg} \mathrm{g}^{-1}$ for RMN, ATMN and BTMN, respectively. The Langmuir equilibrium constant increased from 0.109 to $0.235 \mathrm{~L} \mathrm{mg}^{-1}$ in the order $\mathrm{ATMN}<\mathrm{BTMN}<\mathrm{RMN}$, implying that $\mathrm{Cr}(\mathrm{VI})$ formed stronger bonds with RMN and BTMN.

The Freundlich $K_{\mathrm{F}}$ values obtained for RMN, ATMN and BTMN were 13.86, 10.48 and 9.71, respectively (Table 2). The calculated $n_{\mathrm{F}}$ values were larger than unity, giving $1 / n_{\mathrm{F}}$ values between 0 and 1 , indicating favorable biosorption in this order RMN $>$ ATMN $>$ BTMN.

The Redlich-Peterson model which best describes the biosorption process over a wide range of concentrations was evaluated and showed that the Redlich-Peterson constants $k_{\mathrm{rp}}$ and $a_{g}$ increased in the order RMN, BTMN and ATMN. This is different from what has been observed with previous models. The exponent $g$ values were closer to 1 , which implied a homogenous coverage consistent with the Langmuir model. The adsorption capacities obtained from the Sips model were $43.69,40.42$ and $39.77 \mathrm{mg} \mathrm{g}^{-1}$ for

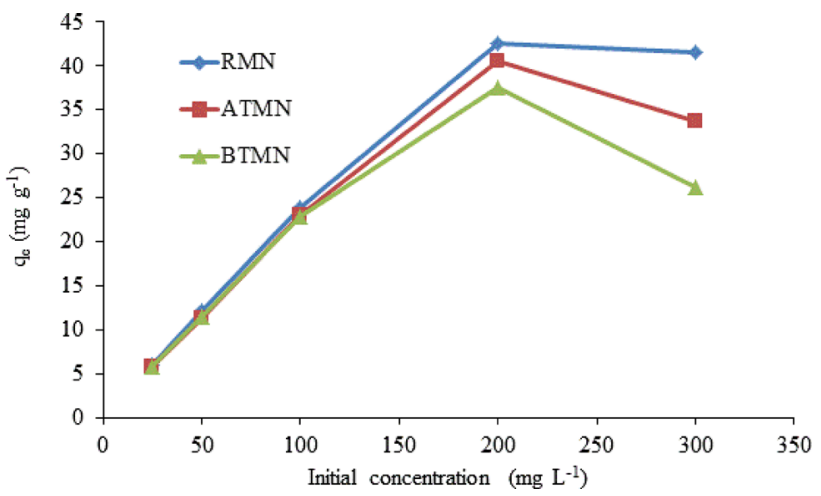

Fig. 5 Effect of initial concentration (condition: solution concentration $100 \mathrm{mg} \mathrm{L}^{-1}$; amount of adsorbent $0.2 \mathrm{~g}$; solution volume $25 \mathrm{~mL}$; $\mathrm{pH} 2$; contact time $10 \mathrm{~h}$ )

RMN, ATMN and BTMN, respectively. This trend is consistent with the Langmuir model capacities. The Sips adsorption capacities were closer to the experimental values. The Sips exponent (ms) values were 1.215, 1.908 and 1.345 for RMN, ATMN and BTMN, respectively. Two of these values are close to one which showed that Sips approached Langmuir for RMN and BTMN. This could be supported by the differences in the respective adsorption capacities from the Langmuir and Sips model observed for the corresponding samples, 1.54, 2.67 and 4.41 for RMN, BTMN and ATMN, respectively. The bigger the difference in $q_{m}$, the lesser the models converge. In this case, the Sips result of the RMN and BTMN described Langmuir better than ATMN. Since the data in Table 2 could not be described perfectly by any model studied, the overall mechanism for $\mathrm{Cr}(\mathrm{VI})$ removal by Macadamia could be described as a complex involving complexation, ion exchange, reduction and/or electrostatic interaction. Similar deductions were made in the literature (Ramrakhiani et al. 2011). Treatment with $\mathrm{NaOH}$ and $\mathrm{HCl}$ in this case led to a decreased efficiency due to the removal of active functional groups.

Table 3 shows the actual $R_{L}$ values obtained from Eq. 5 . All the values are between 0 and 1, implying favorable adsorption of $\mathrm{Cr}(\mathrm{VI})$ by RMN, ATMN and BTMN. The $R_{L}$ values for RMN were closer to zero, which further indicated that the adsorption was likely irreversible (implying stronger bonds between adsorbate and adsorbent or that $\mathrm{Cr}(\mathrm{VI})$ was changed to a different form ( $\mathrm{Cr}(\mathrm{III})$ by reduction), while those of ATMN and BTMN were closer to 1 which implied a linear adsorption. The Chi-square, $\chi^{2}$, statistic test described by Eq. 12 measures the sum of the squares of the difference between the experimental adsorption capacity $\left(q_{e}\right)$ and $q_{m}$ predicted using models, each divided by the corresponding $q_{m}$. 
Table 2 Parameters of adsorption isotherm models for $\mathrm{Cr}(\mathrm{VI})$ sorption

\begin{tabular}{|c|c|c|c|c|}
\hline Models & Parameters & $\mathrm{RMN}$ & ATMN & BTMN \\
\hline Langmuir & $q_{m}\left(\mathrm{mg} \mathrm{g}^{-1}\right)$ & 45.23 & 44.83 & 42.44 \\
\hline \multirow[t]{4}{*}{$q_{e}=q_{\max } b C_{e} /\left(1+b C_{e}\right)$} & $b\left(\mathrm{~L} \mathrm{mg}^{-1}\right)$ & 0.235 & 0.109 & 0.115 \\
\hline & $r^{2}$ & 0.986 & 0.945 & 0.989 \\
\hline & $\chi^{2}$ & 0.61 & 2.92 & 0.56 \\
\hline & $\mathrm{MSq}^{\mathrm{a}}$ & 5.30 & 18.45 & 3.22 \\
\hline \multirow[t]{5}{*}{ Freundlich $q_{e}=K_{\mathrm{F}} C_{e}^{1 / n f}$} & 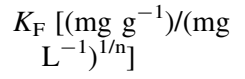 & 13.86 & 10.48 & 9.71 \\
\hline & $n_{\mathrm{F}}$ & 4.02 & 3.47 & 3.36 \\
\hline & $r^{2}$ & 0.813 & 0.763 & 0.87 \\
\hline & $\chi^{2}$ & 9.02 & 10.75 & 5.96 \\
\hline & $\mathrm{MSq}$ & 69.00 & 77.95 & 38.12 \\
\hline \multirow[t]{6}{*}{ Redlich-Peterson $q_{e}=k_{\mathrm{rp}} C_{e} /\left(1+a_{\mathrm{rp}} C_{e}^{g}\right)$} & $k_{\mathrm{rp}}\left(\mathrm{L} \mathrm{g}^{-1}\right)$ & 8.38 & 3.44 & 4.01 \\
\hline & $a_{g}\left(\mathrm{~L} \mathrm{mg}^{-1}\right)^{g}$ & 0.1149 & 0.0215 & 0.0538 \\
\hline & $g$ & 1.107 & 1.269 & 1.119 \\
\hline & $r^{2}$ & 0.998 & 0.989 & 0.997 \\
\hline & $\chi^{2}$ & 0.19 & 0.71 & 0.16 \\
\hline & $\mathrm{MSq}$ & 1.153 & 5.38 & 1.29 \\
\hline \multirow[t]{6}{*}{ Sips $q_{e}=q_{\mathrm{ms}} k_{\mathrm{s}} C_{e}^{\mathrm{ms}} /\left(1+k_{\mathrm{s}} C_{e}^{\mathrm{ms}}\right)$} & $q_{\mathrm{ms}}\left(\mathrm{mg} \mathrm{g}^{-1}\right)$ & 43.69 & 40.42 & 39.77 \\
\hline & $k_{\mathrm{s}}\left(\mathrm{L} \mathrm{mg}^{-1}\right)^{m}$ & 0.201 & 0.0257 & 0.0716 \\
\hline & $\mathrm{ms}$ & 1.215 & 1.908 & 1.345 \\
\hline & $r^{2}$ & 0.991 & 0.989 & 0.998 \\
\hline & $\chi^{2}$ & 0.35 & 1.46 & 0.23 \\
\hline & $\mathrm{MSq}$ & 5.02 & 5.58 & 0.89 \\
\hline
\end{tabular}

${ }^{\mathrm{a}} \mathrm{MSq}$ - sum of square error divided by degrees of freedom

Table 3 Langmuir separation factor for biosorption of $\mathrm{Cr}(\mathrm{VI})$ onto RMN, ATMN and BTMN

\begin{tabular}{llll}
\hline Initial concentration $\left(\mathrm{mg} \mathrm{L}^{-1}\right)$ & $\begin{array}{l}\text { RMN } \\
R_{L} \text { value }\end{array}$ & ATMN & BTMN \\
\hline 25 & 0.145 & 0.984 & 0.898 \\
50 & 0.078 & 0.992 & 0.898 \\
100 & 0.041 & 0.996 & 0.897 \\
200 & 0.021 & 0.998 & 0.897 \\
300 & 0.014 & 0.998 & 0.897 \\
\hline
\end{tabular}

$X^{2}=\sum \frac{q_{e}-q_{\mathrm{m}}}{q_{\mathrm{m}}}$

If $\chi^{2}$ is small, it implies that the experimental data were closer to the model results and if $\chi^{2}$ is large, the results are far apart. According to this explanation, the models did fit the experimental results in the order RedlichPeterson $>$ Sips $>$ Langmuir $>$ Freundlich .

Table 4 shows the comparison of adsorption capacities from different biosorbents. A direct comparison of sorbents is not totally possible due to different treatment methods and experimental conditions used. The Macadamia nutshell powdered materials investigated here had comparable biosorption capacities to other sorbents used for $\mathrm{Cr}(\mathrm{VI})$ removal. The Langmuir model biosorption capacities $\left(q_{m}\right)$ were 45.23, 44.83 and $42.44 \mathrm{mg} \mathrm{g}^{-1}$ for RMN, ATMN and BTMN, respectively.

\section{Effect of contact time}

Figure 6 shows the adsorption capacity of RMN, ATMN and BTMN as a function of time. Contact time was varied from 10 to $600 \mathrm{~min}$. It was observed that between 10 and 200 min the uptake of $\mathrm{Cr}(\mathrm{VI})$ was almost linear, implying faster removal kinetics due to the concentration gradient created by the large number of available adsorption sites (Albadarin et al. 2011). From 200 to $600 \mathrm{~min}$, the uptake slowed down, as shown by the curvelinear part of the graph. After $600 \mathrm{~min}$, all three materials reached equilibrium for adsorption, suggesting that optimum removal was achieved at $600 \mathrm{~min}$ for all three materials. Therefore, $600 \mathrm{~min}$ was used in subsequent experiments. The longer equilibration time (600 $\mathrm{min}$ ) attained was attributable to the materials having deeper embedded adsorption sites that were not easily accessible or that the surface of the materials was slightly hydrophobic causing repulsion of $\mathrm{Cr}(\mathrm{VI})$. 
Table 4 Comparison of binding capacities

\begin{tabular}{|c|c|c|c|c|}
\hline Adsorbent & Treatment & $\mathrm{pH}$ & $\begin{array}{l}\text { Adsorption capacity } \\
\left(\mathrm{mg} \mathrm{g}^{-1}\right)\end{array}$ & References \\
\hline Macadamia nutshell (RMN) & Deionized water (raw) & 2 & 45.23 & This study \\
\hline Macadamia nutshell (ATMN) & $0.1 \mathrm{M} \mathrm{HCl}$ & 2 & 44.83 & This study \\
\hline Macadamia nutshell (BTMN) & $0.1 \mathrm{M} \mathrm{NaOH}$ & 2 & 42.44 & This study \\
\hline T. clypeatus biomass & Heat & 5 & 9.92 & Ramrakhiani et al. (2011) \\
\hline Oedogonium hatei & Raw & 2 & 28.99 & Gupta and Rastogi (2009) \\
\hline Oedogonium hatei & $0.1 \mathrm{M} \mathrm{HCl}$ & 2 & 35.2 & Gupta and Rastogi (2009) \\
\hline Sugarcane bagasse & - & 2 & 1.76 & Aloma et al. (2014) \\
\hline Coconut coir & - & 2 & 6.3 & Gonzalez et al. (2008) \\
\hline Mango sawdust & Deionized water (raw) & 2 & 37.73 & Vinodhini and Das (2010) \\
\hline Neem sawdust & Deionized water (raw) & 2 & 58.82 & Vinodhini and Das (2010) \\
\hline Caryota urens inflorescence waste biomass & Distilled water & 2 & 100 & $\begin{array}{c}\text { Rangabhashiyam and } \\
\text { Selvaraju (2015b) }\end{array}$ \\
\hline Sugarcane bagasse & Hot deionized water & 2 & 5.75 & Garg et al. (2007) \\
\hline Maize corncobs & Hot deionized water & 2 & 3 & Garg et al. (2007) \\
\hline Jatropha oil cake & Hot deionized water & 2 & 11.75 & Garg et al. (2007) \\
\hline Sargassum mиticum & Deionized water & 2 & 196.1 & Bermudez et al. (2012) \\
\hline
\end{tabular}

The PFO, PSO rate models and Elovich model were utilized to study the time dependence of $\mathrm{Cr}(\mathrm{VI})$ sorption onto Macadamia particles. Table 5 shows the results obtained by fitting the experimental values to the different models. The $\mathrm{q}_{\mathrm{e}}$ values for the PSO model were closer to the $q_{t}$ values for RMN, ATMN and BTMN than $\mathrm{PFO} q_{e}$ and $q_{t}$ values. Using $R^{2}, \chi^{2}$ and MSq, one can conclude that the chemisorption process was better defined in ATMN, BTMN and RMN in that order. The Elovich adsorption rate $\alpha\left(\mathrm{mg} \mathrm{g}^{-1} \mathrm{~min}^{-1}\right)$ and desorption constant $\beta\left(\mathrm{g} \mathrm{mg}^{-1}\right)$ decreased from 3.318 to $1.060 \mathrm{mg} \mathrm{g}^{-1} \mathrm{~min}^{-1}$ and $0.280-0.240 \mathrm{~g} \mathrm{mg}^{-1}$, respectively. It can be deduced that RMN had a higher driving capacity for adsorption of

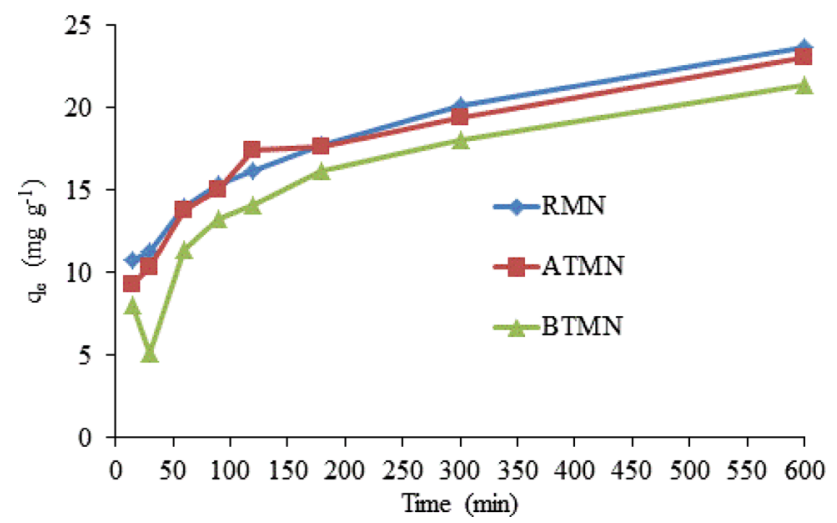

Fig. 6 Effect of contact time on RMN, ATMN and BTMN (conditions: amount of material $0.2 \mathrm{~g}$; solution volume $25.0 \mathrm{~mL}$; solution time 10-600 min; initial concentration of solution $100 \mathrm{mg} \mathrm{L}^{-1}$ )
$\mathrm{Cr}(\mathrm{VI})$. This may be due to the presence of reduction groups on the surface or the crystalline cellulose which increased water retention capacity of RMN. The observations from Elovich were consistent with what was predicted by adsorption models, supporting the RMN $>$ ATMN $>$ BTMN order for the removal efficiency of $\mathrm{Cr}(\mathrm{VI})$.

\section{Sorbent mass}

Figure 7 shows the adsorption capacity as a function of adsorbent mass. $\mathrm{Cr}(\mathrm{VI})$ removal efficiency for all three sorbents increased rapidly while increasing the mass from 0.05 to $0.50 \mathrm{~g}$. The higher the dose of adsorbent, the greater is the surface area and greater is the number of available adsorption and/or reduction sites present for metal ion uptake (Azwa and Yousif 2013). Thereafter, all sorbents seem to attain saturation at about $95 \%$ removal efficiency $(0.2-0.5 \mathrm{~g})$ as the number of active sites decreases. Hence, optimum $\mathrm{Cr}(\mathrm{VI})$ removal $(95 \%)$ was achieved with $0.2 \mathrm{~g}$ sorbent mass and this was used for subsequent studies.

\section{Reusability studies}

Natural adsorbents based on agricultural waste are advocated as cost-effective sorbents. Therefore, it is important to investigate their reusability over cycles of adsorptionregeneration process. In this case, RMN, ATMN or BTMN $(0.2 \mathrm{~g})$ were placed in separate reaction vessels containing 
Table 5 Comparison of kinetic models

\begin{tabular}{|c|c|c|c|c|}
\hline Kinetic models & Parameters & $\mathrm{RMN}$ & ATMN & BTMN \\
\hline \multirow[t]{5}{*}{ Pseudo-first order } & $K_{1}(\min )$ & 0.0278 & 0.023 & 0.0132 \\
\hline & $q_{e}(\mathrm{cal})\left(\mathrm{mg} \mathrm{g}^{-1}\right)$ & 19.23 & 19.52 & 19.29 \\
\hline & $r^{2}$ & 0.853 & 0.906 & 0.910 \\
\hline & $\chi^{2}$ & 1.98 & 3.48 & 6.89 \\
\hline & $\mathrm{MSq}^{\mathrm{a}}$ & 7.69 & 4.94 & 4.52 \\
\hline \multirow[t]{5}{*}{ Pseudo-second order } & $K_{2}\left(\mathrm{~g} \mathrm{mg}^{-1} \mathrm{~min}^{-1}\right)$ & 0.00167 & 0.00139 & 0.00722 \\
\hline & $q_{e}(\mathrm{cal})\left(\mathrm{mg} \mathrm{g}^{-1}\right)$ & 21.78 & 22.10 & 22.40 \\
\hline & $r^{2}$ & 0.934 & 0.963 & 0.942 \\
\hline & $\chi^{2}$ & 4.64 & 1.22 & 3.90 \\
\hline & $\mathrm{MSq}$ & 3.43 & 1.93 & 2.95 \\
\hline \multirow[t]{5}{*}{ Elovich $q t=1 / \beta(\ln (\alpha \beta)+\ln t)$} & $\alpha\left(\mathrm{mg} \mathrm{g}^{-1} \min ^{-1}\right)$ & 3.318 & 2.430 & 1.060 \\
\hline & $\beta\left(\mathrm{g} \mathrm{mg}^{-1}\right)$ & 0.280 & 0.264 & 0.240 \\
\hline & $r^{2}$ & 0.988 & 0.991 & 0.951 \\
\hline & $\chi^{2}$ & 0.34 & 0.24 & 2.43 \\
\hline & $\mathrm{MSq}$ & 0.64 & 0.45 & 2.51 \\
\hline
\end{tabular}

${ }^{\mathrm{a}} \mathrm{MSq}$ - sum of square error divided by degrees of freedom

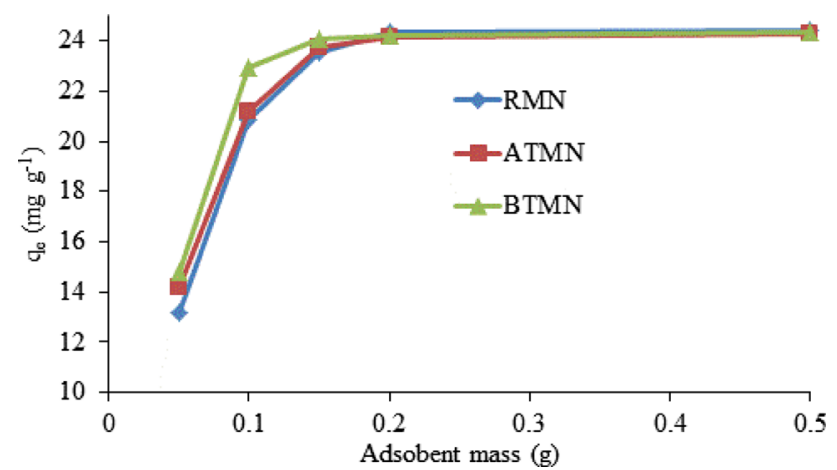

Fig. 7 Effect of dosage (conditions: solution concentration $100 \mathrm{mg}$ $\mathrm{L}^{-1}$; initial $\mathrm{pH} 2$; solution volume $25 \mathrm{~mL}$; contact time $10 \mathrm{~h}$ )

a Cr(VI) solution $\left(100 \mathrm{mg} \mathrm{L}^{-1}\right)$ and stirred for $10 \mathrm{~h}$. Particles were removed by centrifugation and desorbed with a $0.1 \mathrm{M} \mathrm{NaOH}$ solution $(10 \mathrm{~mL})$. Figure 8 shows that all three sorbents investigated could be used more than once with recoveries of greater than $80 \%$. The decreased recoveries especially with RMN could be attributed to modification of the surface during $\mathrm{Cr}(\mathrm{VI})$ leaching by $\mathrm{NaOH}$ solution.

\section{Conclusions}

Three forms of Macadamia nutshell biosorbents viz., raw, acid-treated and base-treated were evaluated for adsorption of $\mathrm{Cr}(\mathrm{VI})$ from aqueous solution in batch mode. $\mathrm{NaOH}$ treatment (BTMN) gave a higher percent extraction of

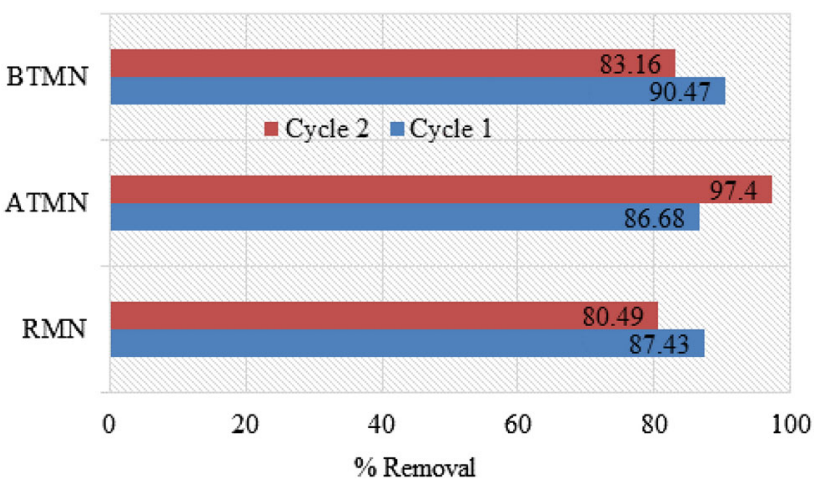

Fig. 8 Adsorption-desorption cycles (conditions: solution concentration $100 \mathrm{mg} \mathrm{L}^{-1}$; initial $\mathrm{pH} 2$; solution volume $25 \mathrm{~mL}$; contact time $10 \mathrm{~h}$ )

hemicellulose fraction that affects its $\mathrm{Cr}(\mathrm{VI})$ removal efficiency. The adsorbent materials were characterized by FTIR, SEM and TGA. The FTIR spectra before and after adsorption of $\mathrm{Cr}(\mathrm{VI})$ revealed significant changes in the region of 1637 and $1455 \mathrm{~cm}^{-1}$ which were attributed to the participation of carboxylate and methoxyl groups, respectively, in the removal of $\mathrm{Cr}(\mathrm{VI})$. SEM images revealed that ATMN and BTMN had retained the flaky structural backbone observed in raw Macadamia, implying that the treatment procedures were not excessively harsh to destroy the structure of materials. The optimal operating conditions for removal of $\mathrm{Cr}(\mathrm{VI})$ were found to be at $\mathrm{pH} 2$, concentration $100 \mathrm{mg} \mathrm{L}^{-1}$, adsorbent mass $0.2 \mathrm{~g}$ and initial contact time of $10 \mathrm{~h}$, indicating that adsorption is strongly dependent on the mentioned parameters. The maximum 
binding capacities obtained for RMN, ATMN and BTMN were $45.2,44.8$ and $42.4 \mathrm{mg} \mathrm{g}^{-1}$, respectively. It was also demonstrated that the prepared materials can be recycled more than once with removal efficiencies greater than $80 \%$. The presence of electron-donating groups on RMN, ATMN and BTMN facilitated the anionic adsorption-reduction mechanism. The mode of adsorption for all three sorbents investigated could not be described by a single model due to complex processes involved. It was found that the acid and base treatments of Macadamia adsorbents decreased the percent removal of $\mathrm{Cr}(\mathrm{VI})$ due to extraction of electron donor groups from RMN. However, when comparing the adsorption capacities in Table 4 with other biomaterials, it can be concluded that Macadamia nutshells are good sorbents for the removal of $\mathrm{Cr}(\mathrm{VI})$ from aqueous solutions.

Acknowledgments The authors would like to thank the National Research Foundation (TTK13061018779) and the Vaal University of Technology for providing financial support.

Open Access This article is distributed under the terms of the Creative Commons Attribution 4.0 International License (http:// creativecommons.org/licenses/by/4.0/), which permits unrestricted use, distribution, and reproduction in any medium, provided you give appropriate credit to the original author(s) and the source, provide a link to the Creative Commons license, and indicate if changes were made.

\section{References}

Abdolali A, Guo WS, Ngo HH, Chen SS, Nguyen NC, Tung KL (2014) Typical lignocellulosic wastes and by-products for biosorption process in water and wastewater treatment: a critical review. Bioresour Technol 160:57-66

Albadarin A, Al-Muhtaseb A, Al-laqtah N, Walker G, Allen S, Ahmad M (2011) Biosorption of toxic chromium from aqueous phase by lignin: mechanism, effect of other metal ions and salts. Chem Eng J 169:20-30

Aloma I, Rodriguez I, Calero M, Blazquez G (2014) Biosorption of $\mathrm{Cr}^{6+}$ from aqueous solution by sugarcane bagasse. Desalin Water Treat 52(31-33):5912-5922

Altun T, Pehlivan E (2012) Removal of $\mathrm{Cr}(\mathrm{VI})$ from aqueous solutions by modified walnut shells. Food Chem 132:693-700

An Z, Zhang H, Wen Q, Chen Z, Du M (2014) Desalination combined with hexavalent chromium reduction in a microbial desalination cell. Desalination 354:181-188

Azwa ZN, Yousif BF (2013) Thermal degradation study of kenaf fibre/epoxy composites using thermo gravimetric analysis. In: MM Noor, MM Rahman, J Ismail (eds) 3rd Malaysian postgraduate conference (MPC2013) 4-5 July 2013, Sydney, New South Wales, Australia. Paper ID: MPC2013-16; pp 256-264

Basal M, Singh D, Garg V (2009) A comparative study for the removal of hexavalent chromium from aqueous solution by agriculture wastes' carbons. J Hazard Mater 171:83-92

Bermudez Y, Rico IR, Guibal E, Calero de Hoces M, Martin-Lara M (2012) Biosorption of hexavalent chromium from aqueous solution by Sargassum muticum brown alga. Application of statistical design process optimization. Chem Eng J 183:68-76

Boehm HP (1994) Some aspects of the surface chemistry of carbon black and other carbons. Carbon 32:759-769

Dawood S, Sen TK (2012) Removal of anionic dye Congo red from aqueous solution by raw pine and acid-treated pine cone powder as adsorbent: equilibrium, thermodynamic, kinetics, mechanism and process design. Water Res 46:1933-1946

Deng S, Ting Y (2005) Polyethyleneimine-modified fungal biomass as a high capacity biosorbent for $\mathrm{Cr}(\mathrm{VI})$ anions: sorption capacity and uptake mechanisms. Environ Sci Technol 39:8490-8496

Dhakal RP, Ghimire KN, Inoue K (2005) Adsorptive separation of heavy metals from an aquatic environment using orange waste. Hydrometallurgy 79:182-190

Dhal B, Thatoi HN, Das NN, Pandey BD (2013) Chemical and microbial remediation of hexavalent chromium from contaminated soil and mining/metallurgical solid waste: a review. J Hazard Mater 250-251:272-291

Djilali Y, Hadj Elandaloussi EI, Aziz A, de Ménorval L (2012) Alkaline treatment of timber sawdust: a straightforward route toward effective low-cost adsorbent for the enhanced removal of basic dyes from aqueous solutions. J Saudi Chem Soc. doi:10. 1016/j.jscs.2012.10.013

Freundlich H, Helle W (1939) On adsorption in solution. J Am Chem Soc 61:2228-2230

Gardea-Torresdey JL, Tiemann KL, Armendariz V et al (2000) Characterization of $\mathrm{Cr}(\mathrm{VI})$ binding and reduction to $\mathrm{Cr}(\mathrm{III})$ by the agricultural byproducts of Avena monida (Oat) biomass. J Hazard Mater B 80:175-188

Garg U, Kaur M, Garg V, Sud D (2007) Removal of hexavalent chromium from aqueous solution by agricultural waste biomass. J Hazard Mater 140:60-68

Gonzalez MH, Araújo GCL, Pelizaro CB, Menezes EA, Lemos SG, Batista de Sousa G, Nogueira ARA (2008) Coconut coir as biosorbent for $\mathrm{Cr}(\mathrm{VI})$ removal from laboratory wastewater. J Hazard Mater 159:252-256

Greenberg A, Clescerl L, Eaton A (1992) Standard method for the examination of water and wastewater. Washington, DC: American Public Health Association, American Water Works Association, and Water Environment Federation

Gupta VK, Nayak A (2012) Cadmium removal and recovery from aqueous solutions by novel adsorbents prepared from orange peel and $\mathrm{Fe}_{2} \mathrm{O}_{3}$ nanoparticles. Chem Eng J 180:81-90

Gupta V, Rastogi A (2009) Biosorption of hexavalent chromium by raw and acid treated green algae Oedogonium hatei from aqueous solutions. J Hazard Mater 163:396-402

Gupta VK, Rastogi A, Nayak A (2010) Adsorption studies on the removal of hexavalent chromium from aqueous solution using a low cost fertilizer industry waste material. J Colloid Interface Sci 342:135-141

Gupta VK, Nayak A, Agarwal S (2015) Bioadsorbents for remediation of heavy metals: current status and their future prospects. Environ Eng Res 20(1):001-018

Ho Y, McKay G (1999) Pseudo-second order model for sorption processes. Process Biochem 34:451-465

Khani H, Rofouei MK, Arab P, Gupta VK, Vafaei Z (2010) Multiwalled carbon nanotubes-ionic liquid-carbon paste electrode as a super selectivity sensor: application to potentiometric monitoring of mercury ion(II). J Hazard Mater 183:402-409

Langmuir I (1918) The adsorption of gases on plane surfaces of glass, mica and platinum. J Am Chem Soc 40:1361-1403

Lin L, Xu X, Papelis C, Cath TY, Xu P (2014) Sorption of metals and metalloids from reverse osmosis concentrate on drinking water treatment solids. Sep Purif Technol 134:37-45 
Liu B, Huang Y (2011) Polyethyleneimine modified eggshell membrane as a novel biosorbent for adsorption and detoxification of $\mathrm{Cr}(\mathrm{VI})$ from water. J Mater Chem 21:17413-17418

Lu D, Cao Q, Li X, Cao X, Luo F, Shao W (2009) Kinetics and equilibrium of $\mathrm{Cu}$ (II) adsorption onto chemically modified orange peel cellulose biosorbents. Hydrometallurgy 95:145-152

Marshall WE, Johns MM (1996) Agricultural by-products as metal adsorbents sorption properties and resistance to mechanical abrasion. J Chem Technol Biotechnol 66:192-198

Miretzky P, Cirelli AF (2010) $\mathrm{Cr}(\mathrm{VI})$ and $\mathrm{Cr}$ (III) removal from aqueous solution by raw and modified lignocellulosic materials: a review. J Hazard Mater 180:1-19

Mittal A, Mittal J, Malviya A, Kaur D, Gupta VK (2010) Decoloration treatment of a hazardous triarylmethane dye, light green SF (Yellowish) by waste material adsorbents. J Colloid Interface Sci 342:518-527

Mogala M (2014) A profile of the South African Macadamia nuts market value chain 2014. Department of Agriculture, Forestry and Fisheries South Africa, Pretoria

Moodley R, Kindness A, Jonnalagadda S (2007) Chemical composituion of edible Macadamia nuts (Macadamia integrifolia) and impact of soil quality. J Environ Sci Health A Tox Hazard Subst Environ Eng 42(14):2097-2104

Moussavi G, Barikbin B (2010) Biosorption of chromium(VI) from industrial wastewater onto pistachio hull waste biomass. Chem Eng J 162:893-900

$\mathrm{Ng} \mathrm{J}$, Cheung W, McKay G (2002) Equilibrium studies of the sorption of $\mathrm{Cu}(\mathrm{II})$ ions onto chitosan. J Colloid Interface Sci 255:64-74

Ngah WSW, Hanafiah MAKM (2008) Removal of heavy metal ions from wastewater by chemically modified plant wastes as adsorbents: a review. Bioresour Technol 99:3935-3948

Ofomaja A, Ho Y (2007) Effect of $\mathrm{pH}$ on cadmium biosorption by coconut copra meal. J Hazard Mater 139:356-362

Ofomaja A, Naidoo E, Modise J (2010) Surface modification of pine cone powder and its application for removal of $\mathrm{Cu}$ (II) from wastewater. Desalin Water Treat 19:275-285

Paduraru C, Tofan L, Teodosiu C, Bunia I, Tudorachi N, Toma O (2015) Biosorption of zinc(II) on rapeseed waste: equilibrium studies and thermogravimetric investigations. Process Saf Environ 94:18-28

Pagilla K, Canter LW (1999) Laboratory studies on remediation of chromium contaminated soils. J Environ Eng 125:243-248

Parvathi K, Nagendran R (2007) Bioadsorption of chromium from effluent generated in chrome-electroplating unit using Saccharomyces cerevisiae. Sep Sci Technol 42:625-638
Pehlivan E, Cetin S (2009) Sorption of Cr(VI) ions on two Lewatitanion exchange resins and their quantitative determination using UV-visible spectrophotometer. J Hazard Mater 163:448-453

Pholosi A, Ofomaja A, Naidoo E (2013) Effect of chemical extractants on the biosorptive properties of pine cone powder: influence on lead(II) removal mechanism. J Saudi Chem Soc 17:77-86

Ramrakhiani L, Majumder R, Khowela S (2011) Removal of hexavalent chromium by heat inactivated fungal biomass of Termitomyces clypeatus: surface characterization and mechanism of biosorption. Chem Eng J 171:1060-1068

Rangabhashiyam S, Selvaraju N (2015a) Efficacy of unmodified and chemically modified Swietenia mahagoni shells for the removal of hexavalent chromium from simulated wastewater. J Mol Liq 209:487-497

Rangabhashiyam S, Selvaraju N (2015b) Evaluation of the biosorption potential of a novel Caryota urens inflorescence waste biomass for the removal of hexavalent chromium from aqueous solutions. J Taiwan Inst Chem Eng 47:59-70

Redlich O, Peterson D (1959) A useful adsorption isotherm. J Phys Chem 63:1024-1026

Saha B, Orvig C (2010) Biosorbents for hexavalent chromium elimination from industrial and municipal effluents. Coordin Chem Rev 254(23-24):2959-2972

Sun Y, Yue Q, Gao B, Gao Y, Li Q, Wang Y (2013) Adsorption of hexavalent chromium on Arundo donax Linn activated carbon amine-crosslinked copolymer. Chem Eng J 217:240-247

Vinodhini V, Das N (2010) Relevant approach to assess the performance of sawdust as adsorbent of chromium(VI) ions from aqueous solutions. Int J Environ Sci Technol 7:85-92

Wartelle L, Marshall W (2000) Citric acid modified agricultural byproducts as copper ion adsorbents. Adv Environ Res 4:1-7

Webber T, Chakkravorti R (1974) Pore and solid diffusion models for fixed-bed adsorpters. AlChE J 20:228-238

WHO (1993) Guidelines for drinking water quality. World Health Organization

Yang L, Chen J (2008) Biosorption of hexavalent chromium onto raw and chemically modified Sargassum sp. Bioresour Technol 99:297-307

Yang H, Yan R, Chen H, Lee DH, Zheng C (2007) Characteristics of hemicellulose, cellulose and lignin pyrolysis. Fuel 86:1781-1788

Zhao X, Chen J, Chen F, Wang X, Zu Q, Ao Q (2013) Surface characterization of corn stalk superfine power studied by FTIR and XRD. Colloids Surf B Biointerface 104:207-212 